
chemotherapy

\title{
Targeted anti-vascular therapies for ovarian cancer: current evidence
}

\author{
M Hall ${ }^{\star}, 1$, C Gourley ${ }^{2}$, I McNeish ${ }^{3}$, J Ledermann ${ }^{4}$, M Gore ${ }^{5}$, G Jayson ${ }^{6}$, T Perren ${ }^{7}$, G Rustin ${ }^{1}$ and S Kaye ${ }^{5}$ \\ ${ }^{1}$ Department of Medical Oncology, Mount Vernon Cancer Centre, Rickmansworth Road, Northwood, Middlesex HA6 2RN, UK; \\ ${ }^{2}$ Edinburgh Cancer Research UK Centre, MRC IGMM, University of Edinburgh, Crewe Road South, Edinburgh EH4 2XR, UK; \\ ${ }^{3}$ Department of Gynaecological Oncology, Institute of Cancer Sciences, University of Glasgow, Beatson Institute of Cancer \\ Research, Glasgow, Glasgow G61 1BD, UK; ${ }^{4}$ Department of Medical Oncology, UCL Cancer Institute and University College \\ London Hospitals, 90 Tottenham Court Road, London W1T 4TG, UK; ${ }^{5}$ Department of Gynaecological Oncology, Royal Marsden \\ Hospital, Fulham Road, London SW3 6JJ, UK; ' Paterson Institute for Cancer Research, The Christie Hospital, Wilmslow Road, \\ Manchester M20 4BX, UK and 'Institute of Oncology, St James University Hospital, Beckett Street, Leeds LS9 7TF, UK
}

Ovarian cancer presents at advanced stage in around $75 \%$ of women, and despite improvements in treatments such as chemotherapy, the 5-year survival from the disease in women diagnosed between 1996 and 1999 in England and Wales was only $36 \%$. Over $80 \%$ of patients with advanced ovarian cancer will relapse and despite a good chance of remission from further chemotherapy, they will usually die from their disease. Sequential treatment strategies are employed to maximise quality and length of life but patients eventually become resistant to cytotoxic agents. The expansion in understanding of the molecular biology that characterises cancer cells has led to the rapid development of new agents to target important pathways but the heterogeneity of ovarian cancer biology means that there is no predominant defect. This review attempts to discuss progress to date in tackling a more general target applicable to ovary cancer-angiogenesis.

\section{MECHANISMS OF ANTI-ANGIOGENESIS}

Angiogenesis is a requirement to enable cancer growth. To promote vascular sprouting, an angiogenic switch is 'flipped' that promotes factors such as vascular endothelial growth factor (VEGF), fibroblast growth factor (FGF) and angiopoietins and downregulates anti-angiogenics such as thrombospondin-1 and angiostatin. Other mechanisms also exist to vascularise growing cancers such as vessel co-option, mimicry and intussusceptive angiogenesis.

An alternative approach to thwarting angiogenesis is to disrupt the newly established vessels supplying the cancers by vascular disruptive agents (VDAs). These generally cause rapid blood vessel shutdown (within minutes) and subsequent tumour necrosis. Strategies such as photodynamic therapy and radiofrequency ablation, that directly damage tumour masses can be considered VDAs (they also damage existing blood vessels), as are some cytotoxics such as vinca alkaloids that inhibit spindle formation causing cell-cycle arrest in the rapidly dividing endothelial cells as well as malignant populations.
Anti-angiogenic agents such as VEGF/PDGF/FGF inhibitors have been developed, of which the most successful to date is bevacizumab, a humanised monoclonal antibody that inhibits the binding of VEGF to its receptors, VEGFR-1 and VEGFR-2. Neutralising the biological activity of VEGF inhibits the formation of new tumour vessels, causing regression of the remaining tumour vasculature. This slows tumour growth and metastasis (Jain, 2005). Preclinical and early clinical studies show resistance to VEGF inhibition occurring quite quickly and pure VEGF inhibitors such as bevacizumab are best used in conjunction with chemotherapy. However, in contrast to most other anti-vascular agents (Rustin et al, 2003), bevacizumab has shown single-agent activity in ovarian cancer (Burger et al, 2007; Cannistra et al, 2007), but not in many other solid tumour types (Cobleigh et al, 2003; Sandler et al, 2006; Giantonio et al, 2007).

\section{BEVACIZUMAB IN FIRST-LINE OVARIAN CANCER}

Two pivotal studies involving bevacizumab treatment with concomitant standard (3-weekly carboplatin and paclitaxel)

*Correspondence: Dr M Hall; E-mail: marcia.hall@nhs.net

Received 2 May 2012; revised 10 October 2012; accepted 2 November 2012

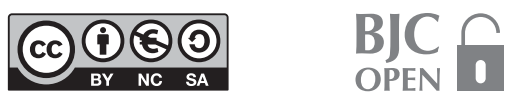


chemotherapy in patients with newly diagnosed ovarian cancer were recently published-ICON7 and GOG218 (Burger et al, 2011; Perren et al, 2011). Both studies incorporated maintenance bevacizumab for set periods of time after the completion of six cycles of chemotherapy. Table 1 details the similarities and differences between the patient populations, therapy administered and outcomes of these studies. In both studies, the advantage of bevacizumab therapy stopped 10 months after the cessation of treatment. In ICON7, control and research arm curves met at 22 months; bevacizumab was administered for a total of 12 months. In GOG218, control and research arm curves met at a later time point of 25 months; but bevacizumab was administered for a total of 15 months. Maintenance treatment with bevacizumab extended the length of PFS $(P<0.001)$.
In GOG218, progression was defined on the basis of rising CA125 alone as well as RECIST and symptomatic relapse, resulting in a PFS of 10.3 vs 14.1 months in favour of maintenance bevacizumab. If however only RECIST and symptomatic relapse are considered, the PFS increased from 12.0 months in the placebo arm to 18.0 months in the maintenance bevacizumab arm. Figure 1 shows that this difference in PFS was very similar to that shown in the high-risk subgroup of ICON7 where CA125 was not taken into account. However, this may not be entirely reliable as the number of patients censored for CA125 is different in each GOG218 study arm. Unfortunately due to $>40 \%$ crossover, the overall survival (OS) benefit of bevacizumab will never be accurately determined from the GOG218 study.

Table 1. Phase III bevacizumab trials in ovary cancer

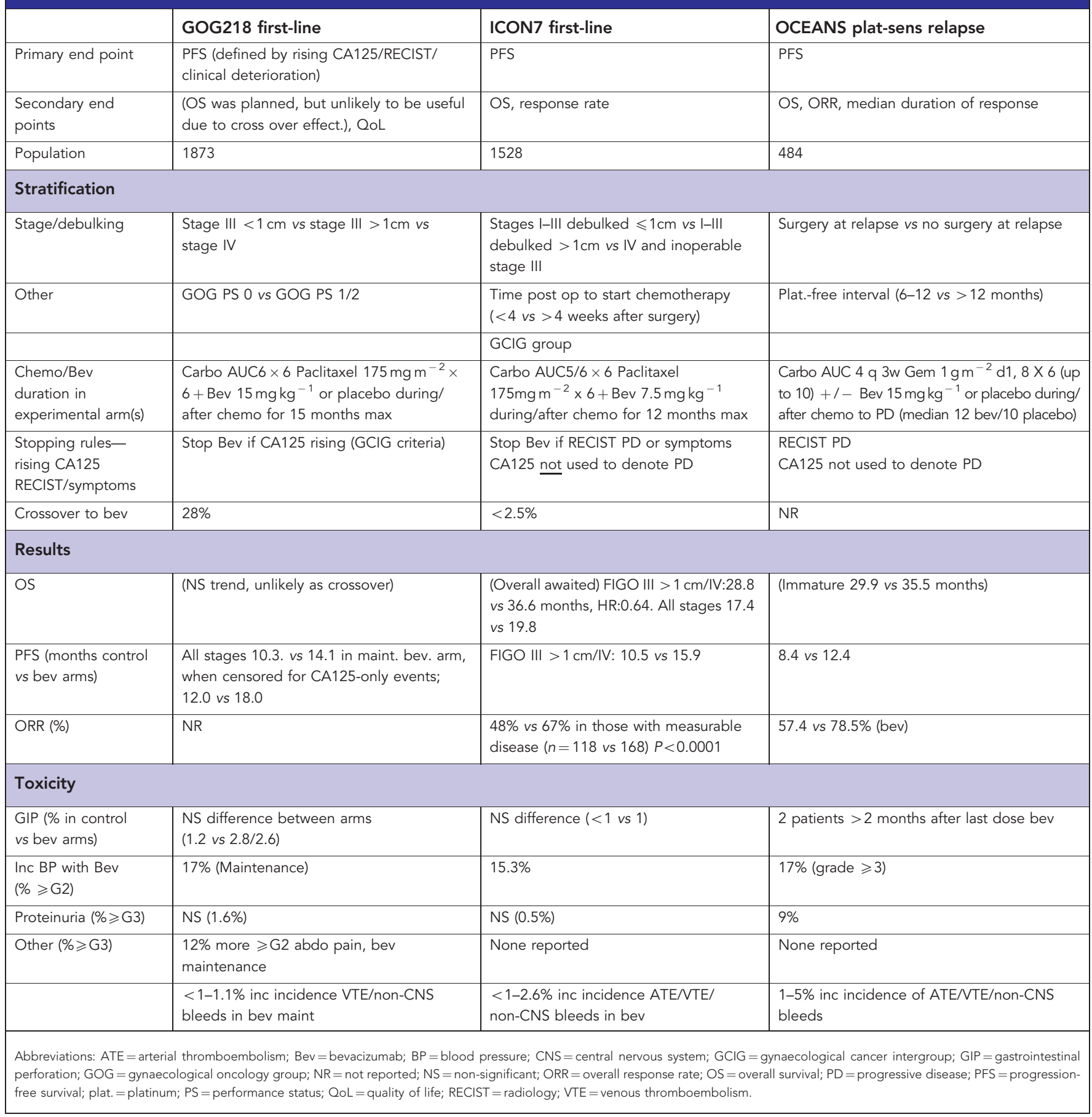




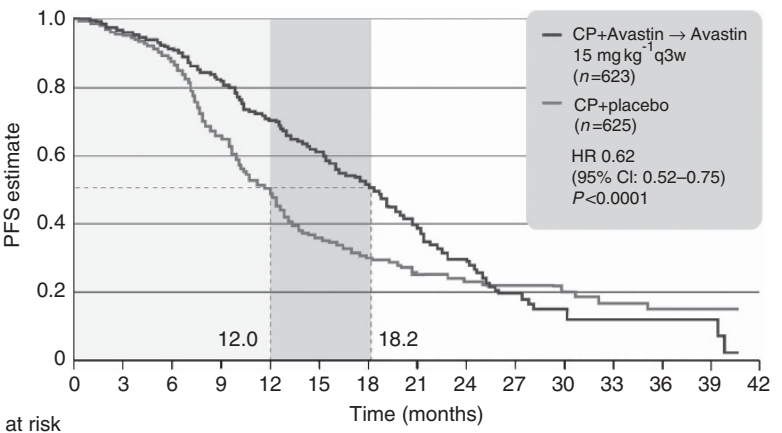

Number at risk

$\begin{array}{lllllllll}\mathrm{CP}+\mathrm{Av} & 623 & 425 & 193 & 74 & 27 & 9 & 5 & 0\end{array}$

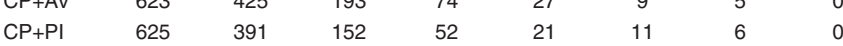

GOG 218: PFS (investigator assessed by

RECIST or symptoms - censored for CA125)

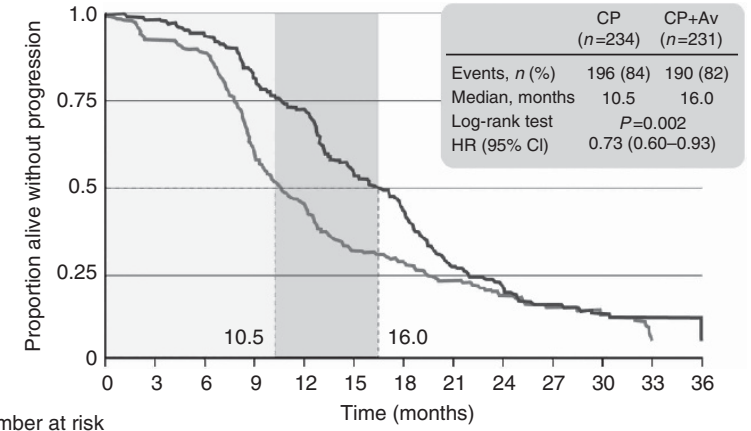

\begin{tabular}{lllccccr}
$\mathrm{CP}+\mathrm{Av}$ & 231 & 213 & 163 & 94 & 35 & 13 & 1 \\
$\mathrm{CP}$ & 234 & 205 & 100 & 63 & 30 & 13 & 5 \\
\multicolumn{8}{c}{$\begin{array}{c}\text { ICON 7: PFS (investigator assessed - } \\
\text { prestratified 'high-risk' subgroup) }\end{array}$}
\end{tabular}

Figure 1. Comparison of the Kaplan-Meier curves for PFS between GOG218 and the high-risk subgroup of ICON7.

The ICON7 study showed an overall PFS advantage for patients receiving bevacizumab of 2.4 months but in a pre-planned analysis of a high-risk subgroup (suboptimally debulked stage III and all stage IV patients, to match and corroborate GOG218) the difference in PFS was 10.5 (control arm) vs 15.9 months (see Table 1). In all, $67 \%$ of the study population in the GOG218 trial were directly comparable to this group as only $33 \%$ were optimally $(<1 \mathrm{~cm})$ debulked $(25 \%$ were stage IV). A final analysis of OS in ICON7 is planned for 2013 but the regulatory authorities requested an interim analysis of OS data, ahead of the required number of events, which was presented in 2012. Analysis of these data in the suboptimally debulked stage III and stage IV patient subset showed a statistically significant OS benefit of 8 months for the group receiving additional maintenance bevacizumab compared with the group receiving chemotherapy alone (HR 0.64, $P=0.002$ ) (Kristensen et al, 2012). These results indicate that disease stage could play a critical role in how tumours respond to VEGF pathway inhibition. However, there is concern as to how cancers might respond when VEGF pathway inhibition stops, perhaps triggering rapid regrowth with the potential for harm (Ebos et al, 2009). Clinical studies to date with VEGF-neutralising antibodies have not shown increases in regrowth after treatment discontinuation (Miles et al, 2011).

\section{WHAT DOSE?: $15 \mathrm{MG} \mathrm{KG}^{-1}$ VS 7.5 $\mathrm{MG} \mathrm{KG}^{-1} \mathrm{Q} 3 \mathrm{~W}$}

The efficacy of the two doses of bevacizumab is very similar (or comparable) in the ICON7 suboptimally debulked stage III/stage IV subset and the GOG218 population, suggesting that the higher dose of $15 \mathrm{mg} \mathrm{kg}^{-1} \mathrm{q} 3 \mathrm{w}$ is unnecessary and that there is no observable dose response above $7.5 \mathrm{mg} \mathrm{kg}^{-1} \mathrm{q} 3 \mathrm{w}$. While the higher dose did not appear to cause significantly more adverse events in GOG218, there is a trend towards a higher incidence of hypertension among patients treated with the $15 \mathrm{mg} \mathrm{kg}^{-1}$ dose, in the relapse studies, but the median time of onset was after 16 cycles of bevacizumab, suggesting a cumulative effect (Aghajanian et al, 2012, abstract). Thus, the consensus among treating UK clinicians, despite the European licence, is that bevacizumab should be used at a dose of $7.5 \mathrm{mg} \mathrm{kg}^{-1}$ in first-line patients with suboptimally debulked disease or inoperable and stage IV patients particularly as there is no obvious benefit seen with the higher dose in GOG218 in this setting. We will be encouraging the National Institute for Clinical Excellence (NICE) to use this dose when assessing its use in first-line ovarian cancer.

The 2011 Cochrane review of bevacizumab in ovarian cancer concluded that from the data available, bevacizumab treatment in first-line OC does not prevent progression, but delays it (Gaitskell et al, 2011). Examining the newer data from GOG218 and ICON7 more closely suggests that bevacizumab does not benefit patients who are optimally debulked (i.e., better prognosis), supporting the concept that different disease 'stages' could influence the response of tumours to anti-vascular interventions. This correlates with more mature data from colorectal cancer where the AVANT and C08 trials showed no benefit (in disease-free intervals) from the addition of adjuvant bevacizumab to patients with stage II/III colorectal cancers. Indeed, data from the AVANT trial suggested that bevacizumab increased the adverse events in these patients (de Gramont et al, 2011).

Suboptimally debulked stage III and IV patients represent $40 \%$ of the presenting ovarian cancer population, all of whom have a very high chance of progression; $50 \%$ do so within 6 months of completing first-line treatment. Responses seen among this population in the ICON7 and GOG218 trials suggest that these patients would achieve an extra 6-8 months PFS if bevacizumab is given as part of their first-line treatment with chemotherapy and maintained until progression. Delaying progression by 6-8 months in a group where half achieve $<6$ months remission, with current standard treatment, is a significant advance.

There are a number of important outstanding questions about the role of bevacizumab therapy in first-line treatment of ovarian cancer: the duration of maintenance treatment, the effect of additional bevacizumab to dose dense cytotoxics, its use when considering interval debulking surgery and its addition to intraperitoneal therapy (IP). Two trials, OCTAVIA $-7.5 \mathrm{mg} \mathrm{kg}^{-1}$ dose and GOG262 (NCT01167712)-15 $\mathrm{mg} \mathrm{kg}^{-1}$ dose, will evaluate the efficacy of pairing bevacizumab with dose dense first-line chemotherapy. Data presented at ASCO 2012 have confirmed the safety of this combination (carboplatin q $21 \mathrm{~d} /$ weekly paclitaxel/bevacizumab). GOG252 (NCT00951496) completed recruitment of 944 patients in April 2011, which confirms the feasibility of concurrent bevacizumab with IP chemotherapy. All treatment arms in this trial contained intravenous bevacizumab and it will be interesting to compare results of this IP/IV platinum and weekly paclitaxel trial with existing data on IP therapy. However, there is no study that is directly asking whether the advantages of either intraperitoneal or dose dense first-line therapy can be enhanced by the addition of bevacizumab.

The updated JGOG data confirming continued OS advantage, at 6 years, for dose dense paclitaxel with 3-weekly carboplatin is likely to make this schedule the treatment of choice in first line, pending corroboration from the ICON8 study (Katsumata et al, 2012). ICON8, however, does not include bevacizumab and if this trial is to complete, this issue will need addressing urgently. Plans to modify the existing MRC sponsored ICON8 study to incorporate 
the addition of bevacizumab yet retain a third arm of dose dense therapy without bevacizumab are most attractive, but execution of these may be challenged by austerity measures.

Two trials, BOOST (AGO-OVAR-16/17, NCT01462890) and RoSiA (NCT01239732) are both examining the feasibility and possible benefits of extending the duration of maintenance bevacizumab (15 $\left.\mathrm{mg} \mathrm{kg}^{-1}\right)$ to $30-36$ months.

\section{BEVACIZUMAB IN RELAPSED OVARIAN CANCER}

Platinum-sensitive relapse. Bevacizumab $\left(15 \mathrm{mg} \mathrm{kg}^{-1}\right)$ has also recently been shown (OCEANS, NCT00434642) to improve PFS in patients with platinum-sensitive relapse, when given in conjunction with carboplatin and gemcitabine for six (up to 10) cycles then as single-agent maintenance until disease progression (Aghajanian et al, 2012). In all, 484 patients with platinum-sensitive relapsed ovarian cancer (ROC) were randomised to receive carboplatin and gemcitabine with or without bevacizumab, which was continued as maintenance until disease progression. No patient received prior bevacizumab. An updated overall safety profile, after an additional 11 months, was similar to that seen at the time of the PFS analysis; proteinuria and hypertension resolved upon discontinuation of bevacizumab in the majority of patients (Aghajanian et al, 2012, abstract).

Results confirmed an advantage for those receiving bevacizumab extending the PFS in this group by 4 months, $P<0.0001$. Suprisingly, no OS benefit has been shown (HR 1.027 at September 2011 analysis), which could be explained partly by crossover but possibly also because most of these patients had several further lines of chemotherapy. Could bevacizumab have a similar impact as another line of chemotherapy, but with a very different toxicity profile?

Platinum-resistant relapse. Phase II exploratory studies of bevacizumab in ovary cancer indicated benefit even in patients who had failed $>3$ lines previous chemotherapy and/or were 'platinum resistant'. Partial response rates of $16-21 \%$, with $27-38 \%$ of patients alive and progression free at 6 months, can be achieved (Burger et al, 2007; Cannistra et al, 2007). Several other retrospective reports detailing bevacizumab therapy in a further 140 patients, confirm a median overall response rate of $57 \%$ (range $53-60 \%$ ) for patients with ROC who have received a median of 4.5 previous cytotoxic therapies (Horsman et al, 2006; Chura et al, 2007; Hurt et al, 2009; Sfakianos et al, 2009). However, G3-4 toxicities occurred in $23-24 \%$ of these populations with a median incidence of gastrointestinal perforation (GIP) of 3\% (range $0-7 \%$ ) and on average these heavily treated platinum-resistant patients only gained a progression-free survival of 4 months (OS of 10-20 months). A randomized trial of chemotherapy with and without bevacizumab (AURELIA) in patients with platinum-resistant ovarian cancer was presented earlier this year (Pujane-Lauraine et al, 2012). This reported an increase in response rate $(P<0.001)$ and a doubling of PFS from 3.4 months to 6.7 months (HR 0.48) in those patients who received bevacizumab in addition to singleagent chemotherapy. The safety profile of bevacizumab in this study was consistent with previous experience in the first- and second-line settings (with a low incidence of GI perforation) but patients at high risk of GI perforation were excluded from this study. Overall survival data are expected in 2013.

Bevacizumab beyond progression. A major omission in the study of bevacizumab in other tumour types such as colorectal cancer is the lack of prospective randomized trials to address the question of whether continuing anti-angiogenic therapy after progression and simply introducing alternative cytotoxic treatment is of any additional benefit in terms of PFS and OS. Observational studies in colorectal cancer in the phase IV setting have suggested that this is the case with an OS advantage of 9-12 months for those who continue bevacizumab beyond progression (Grothey et al, 2008; Cohn et al, 2010). Although there have been a couple of very small single-arm prospective studies that corroborate this (Nakayama et al, 2012), it becomes somewhat unethical to run the randomized large scale phase III trials required to confirm these data and it is most likely that in colorectal cancer the area will remain controversial. A similar situation exists for herceptin in breast cancer (Pegram and Liao, 2012). In ovarian cancer, however, a prospective randomized trial (ENGOT-ov17/MITO 16/MaNGO 2) started recruitment in January 2012 and 470 platinum-sensitive patients progressing after bevacizumab in the first-line setting will be randomized to receive their second-line chemotherapy with or without additional bevacizumab at $15 \mathrm{mg} \mathrm{kg}^{-1}$. Patients will be stratified by bevacizumab-free interval $(<$ or $>16$ weeks) and platinum-free interval (6-12 vs $>12$ months). Results will be eagerly awaited by patients and doctors alike although if they suggest that bevacizumab should be continued, are likely to generate further questions about dose, duration and perhaps most importantly the economic viability of such a strategy.

\section{TOXICITY}

Common toxicities related to bevacizumab include hypertension, proteinuria, haemorrhage and arteriovenous thromboembolic phenomena. Exploration of the frequency of occurrence and management of toxicities of bevacizumab in a variety of other solid tumours are described in detail in Miles et al (2010). Selected toxicity from the pivotal bevacizumab trials in ovary cancer are detailed in Table 2. Sections detailing the common toxicities with particular reference to ovarian cancer data appear below.

\section{HYPERTENSION}

Hypertension is the most common toxicity seen with bevacizumab therapy and this occurs in $10-20 \%$ of treated patients. Looking at all the trials published to date in ovarian cancer, the incidence of hypertension seems to rise with cumulative exposure to bevacizu$\mathrm{mab}$ and is more common in patients receiving the higher $\left(15 \mathrm{mg} \mathrm{kg}^{-1}\right)$ doses (Burger et al, 2011; Perren et al, 2011; Aghajanian et al, 2012, Pujade-Lauraine et al, 2012). In breast cancer, a recent meta-analysis showed that hypertension and proteinuria were the most relevant risks associated with the use of bevacizumab (summary odds ratios of 27.68 for proteinuria and 12.76 for hypertension) but these events were rarely clinically significant (Cortes et al, 2012).

\section{VTE/ATE}

Bevacizumab does not increase the risk of venous thromboembolism; in a recent analysis of $>6000$ patients treated in 10 different non-ovarian randomized cancer trials and compared with controls, the thromboembolic risk varied only according to different tumour type (Hurwitz et al, 2011). This is not quite born out by the evidence from the bevacizumab trials performed in ovarian cancer to date, where there does appear to be a slightly increased risk of VTE in patients receiving additional bevacizumab - see Table 2. It is reported that the incidence of VTE events in patients with advanced ovarian cancer range between $11 \%$ and $42 \%$ (in a clear cell ovarian cancer subgroup) (Duska et al, 2010; Khorana et al, 2012). However, bevacizumab with chemotherapy has been shown to carry a greater risk of ATE than chemotherapy alone in a pooled analysis $(n=1745)$ of five non-ovarian cancer trials, especially in 
Table 2. Selected adverse events for bevacizumab in pivotal ovary cancer trials: GOG218, ICON7 and OCEANS

\begin{tabular}{|c|c|c|c|c|c|c|c|c|}
\hline & \multicolumn{4}{|c|}{$\begin{array}{c}\text { GOG218 } \\
\% \text { affected }^{a}\end{array}$} & \multicolumn{2}{|c|}{$\begin{array}{c}\text { ICON7 } \\
\% \text { affected }^{b}\end{array}$} & \multicolumn{2}{|c|}{$\begin{array}{l}\text { OCEANS } \\
\% \text { affected }^{c}\end{array}$} \\
\hline & \multicolumn{2}{|c|}{$\mathrm{CP}+$ placebo } & \multicolumn{2}{|c|}{$\mathrm{CP}+\mathrm{B} 15->\mathrm{B} 15$} & $\mathrm{CP}$ & $\mathrm{CP}+\mathrm{B7} .5->$ & CG + placebo & CG + B15- $>$ \\
\hline Patients, $n$ & 601 & 483 & 608 & 464 & 753 & 745 & 233 & 247 \\
\hline Cycles & 2906 & 4059 & 2891 & 4677 & NR & NR & NR & NR \\
\hline Treatment phase & Cycles 2-6 & Cycles 7-22 & Cycles 2-6 & Cycles 7-22 & Overall & Overall & Overall & \\
\hline \multicolumn{9}{|c|}{ Selected adverse events (grade when limited) } \\
\hline $\begin{array}{l}\text { Gl events (perforation/fistula/ } \\
\text { necrosis/leak) (> G2) }\end{array}$ & 1.0 & $<1.0$ & 2.5 & 0.2 & $<1$ & 1.3 & $<1$ & $<1^{d}$ \\
\hline Hypertension ( $\geqslant G 2)$ & 3.5 & 4.6 & 9.9 & 17.0 & 2.1 & 18.3 & $0.4(\geqslant G 3)$ & $17.8(\geqslant G 3)$ \\
\hline Proteinuria ( $\geqslant G 3$ ) & 0.3 & 0.4 & 0 & 2.2 & $<1$ & $<1$ & 0.9 & 9.7 \\
\hline $\begin{array}{l}\text { Venous Thromboembolic } \\
\text { Event (VTE) }\end{array}$ & 4.3 & 1.9 & 4.4 & 3.0 & $1.7 \geqslant G 3$ & $4.3 \geqslant G 3$ & $2.6 \geqslant G 3$ & $4 \geqslant G 3$ \\
\hline $\begin{array}{l}\text { Arterial Thromboembolic } \\
\text { Events (ATE) (all grades) }\end{array}$ & 0.7 & 0.2 & 0.5 & 0.2 & 1.5 & 3.6 & 0.9 & 2.8 \\
\hline Wound healing complications & 1.8 & 1.2 & 2.1 & 1.1 & 2.1 & 5.0 & $0 \geqslant G 3$ & $0.8 \geqslant G 3$ \\
\hline CNS bleeding (all grades) & 0 & 0 & 0 & 0.4 & 0 & $<1$ & 0.4 & 0.8 \\
\hline Non-CNS bleeding $(\geqslant G 3)$ & 0.5 & 0.4 & 1.6 & 0.6 & $<1$ & $<1$ & 0.9 & 5.7 \\
\hline RPLS (all grades) & 0 & 0 & 0 & 0.2 & $<1$ & $<1$ & 0 & 0.8 \\
\hline \multicolumn{9}{|c|}{ 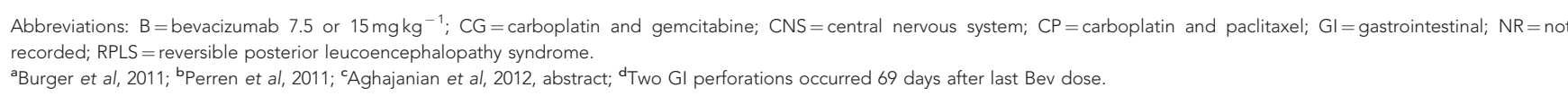 } \\
\hline
\end{tabular}

patients over the age of 65 years (Cassidy et al, 2010) But in pivotal trials, including ovary cancer trials, stroke, TIA and myocardial infarction only occurred in $\leqslant 3 \%$ of patients. Adverse events from GOG218 and OCEANS would suggest that the combination of chemotherapy with bevacizumab carries a higher ATE risk than maintenance bevacizumab alone (Table 2). If ATE occurs, bevacizumab should be discontinued.

\section{WOUND HEALING}

The approximate mean elimination half life of bevacizumab is $18-$ 20 days; published clinical trials have taken this into account so that bevacizumab therapy is delayed until $>28$ days from any planned surgery. There is no evidence of any greater incidence of wound healing problems in published or ongoing trials in any tumour type to date that involve interval surgery for bevacizumabtreated patients (Okines et al, 2011; Javier Cortes et al, 2012). The GOG213 (NCT00565851) study, carboplatin and paclitaxel for platinum-sensitive relapse with or without bevacizumab after optional secondary debulking surgery, will report a more accurate risk with respect to wound healing in ROC patients.

\section{GASTROINTESTINAL PERFORATION}

The pathophysiological mechanism by which bowel perforations occur during bevacizumab therapy is unknown but possible mechanisms include

- necrosis of tumour on serosal surfaces with weakening of adjacent intestinal wall,

- bowel injury at surgery with delayed wound healing,

- vasoconstriction and/or thrombosis of intestinal mesenteric vessels,
- other GI-related risk factors such as bowel obstruction or diverticulitis,

- prior surgical interventions.

These proposed mechanisms of action support the trend in those receiving bevacizumab for ovary cancer where higher rates of GIP occur in patients with documented serosal plaques or bowel obstruction at study entry.

The reported incidence of perforations in the single-arm phase II trials of bevacizumab in recurrent ovarian cancer varies widely, but is as high as $11 \%$ in a study where 40 of the 44 patients had radiographic bowel involvement at study entry (Cannistra et al, 2007). However, in an analysis of combined data in relapsed ovary cancer patients, the overall risk with bevacizumab treatment was 5.4\% (Han and Monk, 2007). Overall this represents a higher risk than in metastatic colorectal cancer patients treated with bevacizumab where it is estimated to be $1.9 \%$ (Kabbinavar et al, 2012).

Sfakianos et al (2009) remind us that there is an underlying incidence of GIP in patients with multiply ROC, whether or not they have received bevacizumab. Their retrospective review puts the relative risk for developing a GIP/fistula as a consequence of the addition of bevacizumab to further chemotherapy, in this setting at 1.09 . It does not diminish the potentially devastating consequences of GIP with a 30-day mortality of 50\% (Miller et al, 2001; Diaz et al, 2010).

The entry criteria for the single-agent Burger study of 2007 mandated 2 or fewer lines of previous therapy, which is perhaps why no GIP was reported. No protocol-specified GIP was reported in the OCEANS study either, where patients had not received any chemotherapy for relapse. However, GIP occurred in two patients after progression in this study, both having received bevacizumab $>2$ months prior to this. Other studies suggest that GIP and enteral fistulae occur more frequently during bevacizumab therapy in those who have had $\geqslant 3$ lines of therapy, known fistulae or 
significant bowel wall involvement. Rectovaginal nodularity has an association with an increased incidence of GIP in ovarian cancer patients, even taking imaging findings into account, which may represent a clinical manifestation of significant serosal involvement elsewhere (Richardson et al, 2010).

By contrast, there was only a $1-1.5 \%$ increase in GI perforations recorded in the chemotherapy plus bevacizumab arms of the firstline GOG218 and ICON7 trials compared with the $1 \%$ incidence in patients on chemotherapy alone. GOG218 details (shown in Table 2) reveal that this slight increased incidence of GIP among those treated with additional bevacizumab equalises across both arms once maintenance bevaciaumzab/placebo is established, suggesting that it is the combination of agents that results in a higher risk for this population.

\section{SMALL MOLECULE TYROSINE KINASE INHIBITORS}

There are now several small molecule inhibitors of VEGFR tyrosine kinase (TKI) that have been shown to be active in ovarian cancer. Many of these are multitargeted kinases inhibiting the VEGFR family and others. When assessing TKIs in patients with assessable disease, classical measures of activity such as complete and partial response may not be as informative as in chemotherapy studies, for example in two single-agent studies, one with cediranib, the other pazopanib, only $18 \%$ patients obtained a PR yet the PFS was 5.2 months and 113 days, respectively (Matulonis et al, 2009; Friedlander et al, 2010). The populations of both studies were multiply relapsed, platinum-resistant patients, the end point of the Matulonis study was determined as 'clinical benefit rate' (improved in $30 \%)$ - the sum of PR (17\%) and SD (13\%) patients. Other phase II studies with sunitinib or sorafenib have reported similar results (Biagi et al, 2011; Matei et al, 2011). All these studies, conducted in a heterogenous population, make interpretation of response, or even PFS difficult. The side effects of these drugs are similar, with hypertension, fatigue and diarrhoea being most commonly found. Nevertheless, as experience grows most of these are manageable by altering the dose or schedule, and introducing short 'drug holidays' as part of longer-term treatment.

Randomised trials provide a better approach to evaluating this class of drugs, eliminating some of the bias of patient selection and allowing a more objective assessment of side effects in a population that often have disease-related symptoms. In a randomised maintenance trial nintedanib (BIBF1120)/placebo was given to patients who had responded and completed treatment for relapsed disease (Ledermann et al, 2011). The trial was statistically powered to assess PFS at 36 weeks; this was $16 \%$ in patients receiving nintedanib and $5 \%$ on placebo ( $\mathrm{HR} 0.65$, $P=0.06)$ and the drug was taken forward to phase III in the firstline setting. There was a higher rate of nausea, vomiting, diarrhoea and disturbed liver function tests in patients on nintedanib but only rarely of clinical significance; most patients continued treatment until PD.

Other larger phase III trials are also in progress, two in first-line treatment (pazopanib/placebo, NCT00866697 and nintedanib/ placebo, AGO-OVAR-12, NCT01015118) and one at first platinumsensitive relapse (cediranib/placebo, ICON6, NCT00532194). Virtually all of these trials involve concomitant TKIs with chemotherapy, but pazopanib is unable to be given with many cytotoxics due to excess adverse events. The TKIs are then continued as maintenance for up to 2 years or PD in each trial. The first-line trials have completed recruitment; PFS is the primary end point. In ICON6, an academically led 3-arm study in relapse where two experimental arms of cediranib were given with chemotherapy then as maintenance until progression, or only with chemotherapy, switching to placebo maintenance, the trial end point has been modified to have PFS as the primary end point as the manufacturer decided not to develop the drug further. The trial is still ongoing, but closed to recruitment with 486 patients.

\section{ANGIOPOEITIN PEPTIBODIES}

Angiopoetins are circulating protein growth factors (Ang-1/Ang-2) that promote angiogenesis by interacting with Tie2 receptors. The anti-angiopoetin $1 / 2$ peptibody (a first-in-class peptide-Fc fusion protein), AMG386, given in combination with weekly paclitaxel has demonstrated prolongation of PFS in a recent randomized phase II trial (4.6-7.2 months, HR 0.76) (Karlan et al, 2012). Side effects included oedema, hypertension and thromboembolic events. A phase III study, TRINOVA-1 (NCT01204749) has closed to recruitment, randomizing patients with ROC between AMG 386 or placebo in combination with weekly paclitaxel. The primary outcome measure is progression-free survival. Phase II trials of PLD with and without AMG 386 in patients with platinumresistant ROC are also underway (TRINOVA-2 NCT01291254) as is a phase III double blind, placebo-controlled study of AMG386 with carboplatin and paclitaxel in patients with newly diagnosed ovarian cancer (TRINOVA-3 NCT01493505).

\section{VASCULAR DISRUPTIVE AGENTS}

Conventionally, the molecules known as VDAs are either derivatives of flavone acetic acid that are thought to act by invoking cytokine release such as TNFa or are tubulin-binding agents such as combretastatin. The selectivity of the tubulinbinding agents is thought in part to be due to the rapid division of endothelial cells but these agents also cause distortion of immature endothelial cells which lack a pericyte coating. This distortion induces thrombosis and vessel collapse (Horsman and Siemann, 2006). VDAs have minimal single-agent activity as despite causing necrosis of the main cancer mass, a viable rim is left, which repopulates the cancer. It appears that VDAs eliminate cells that are less well vascularised where the delivery of systemically administered chemotherapeutic drugs is limited, and which are resistant to radiotherapy, while cytotoxic drugs exert their greatest effects on cells in the viable rim of tumour tissue that survive the VDA treatment. Preclinical and some early clinical results suggest that greater efficacy can be obtained as combination therapyVDAs with cytotoxic agents, active against the rapidly repopulating tumour rim, or with VEGF inhibitors that act by blocking repopulation with circulating endothelial progenitor cells. Unlike the chronic dosing schedule required to prevent angiogenesis, VDAs should be effective given as intermittent doses. Early singlearm phase II studies in patients have shown that the addition of VDAs such as vadimezan (DMXAA) or fosbretabulin (CA4P) to standard chemotherapy is well tolerated and appears to produce a higher response rate in the populations studied to date, for example $29 \%$ response by RECIST or GCIG CA125 criteria in platinum-resistant patients (McKeage, 2011; Zweifel et al, 2011). Recruitment to two phase II studies, ombrabulin/placebo with conventional carboplatin and paclitaxel chemotherapy and bevacizumab with or without fosbretabulin are underway in platinum-sensitive ovarian cancer in the United States (NCT01305213, NCT01332656).

\section{CHEMOTHERAPY SCHEDULING}

Weekly paclitaxel. Many chemotherapy drugs are believed to possess anti-angiogenic effects themselves (Miller et al, 2001). The 
mechanism is that tumour endothelial cells are likely to be actively cycling at the site of (neo)angiogenesis and thus susceptible to chemotherapy-induced damage; this damage is less likely to be repaired with repeated weekly chemotherapy than with conventional 3-weekly administrations. Belotti et al (1996) first reported that low-dose paclitaxel was specifically toxic to endothelial cells; additional paclitaxel effects on the endothelial cells include cellcycle delay rather than arrest, alterations in microtubule dynamics and blocking of bFGF and VEGF-induced vascularisation as well as a reduction of new vessel infiltration in vitro (Belotti et al, 1996; Pasquier et al, 2005). Only one study has attempted to measure vascular flow in women with ovarian cancer treated with paclitaxel, demonstrating a reduction in endothelial flow-mediated dilatation (Vassilakopoulou et al, 2010).

In clinical practice, single agent, weekly paclitaxel has activity in relapsed, platinum-resistant ovarian cancer with response rates ranging from $25 \%$ to $55 \%$. However, median progression-free survival is relatively poor at $\sim 6$ months (Le et al, 2006). There has not been a formal comparison of weekly paclitaxel with other licensed drugs for this platinum-resistant setting such as pegylated liposomal doxorubicin. It is well reported, however, that the addition of other chemotherapy agents (e.g., carboplatin, AUC5 $\mathrm{q} 4 / 52$, or topotecan, $3 \mathrm{mg} \mathrm{m}^{-2}$ per week) to weekly paclitaxel in platinum-resistant ovarian cancer, increases toxicity and does not improve progression-free survival (Lortholary et al, 2011). Two more recent publications suggest that any effect that weekly paclitaxel might have, can be enhanced by the addition of vascular targeting agents such as bevacizumab or AMG386 (O'Malley et al, 2011; Karlan et al, 2012).

\section{METRONOMIC THERAPY}

It is thought that regular low doses of oral chemotherapy (metronomic) might act in a similar mode to that described for weekly paclitaxel, or perhaps through the induction of thrombospondin, an endogenous inhibitor of angiogenesis (Bornstein, 1995). Colorectal and breast oncologists have been using low dose continuous 5 fluorouracil for decades and more recently oral capecitabine. Other agents, such as etoposide, methotrexate and cyclophosphamide, have also shown activity when given metronomically in a number of different tumour types. It is hoped that the addition of anti-angiogenic agents to metronomic chemotherapy will act synergistically to improve response rates and outcomes in ovarian cancer. For example, bevacizumab in combination with metronomic cyclophosphamide resulted in $56 \%$ of 70 platinumresistant patients remaining alive and progression free at 6 months, suggesting an enhanced response rate $(P=0.017)$ (Garcia et al, 2008). Good preclinical evidence also exists for oral topotecan with pazopanib and this prompted a phase I trial, recently reported at ASCO 2012 (Hashimoto et al, 2010; Merritt et al, 2010; Tillmans et al, 2012). Treatment of patients with recurrent (platinum resistant) ovarian cancer with metronomic cyclophosphamide and other agents such as methotrexate, celecoxib and tamoxifen have also been reported (Hall and Rustin, 2010). Combination trials using metronomic cyclophosphamide with oral anti-angiogenic agents such as pazopanib and BIBF1120 are also underway.

\section{FUTURE DIRECTIONS FOR ANTI-ANGIOGENICS}

The main current issues with anti-angiogenic therapy are a lack of accurate predictors of therapeutic efficacy and the inability to prevent resistance to treatment. Pharmacoeconomic concerns are also a major problem in relation to the clinical use of VEGF inhibitors (Hensley, 2011). Further studies of bevacizumab with chemotherapy are warranted in order to optimise the dose and duration of maintenance therapy, and to identify the best time to use this agent, first-line, relapse or both. Clarification of the role of single-agent bevacizumab in managing ascites is required (Kobold et al, 2009). The most promising combinations of anti-angiogenic agents with standard chemotherapy also require further exploration. Most importantly, however, identification of predictive biomarkers in ovary cancer patients is urgently needed for 'individualisation' of VEGF-targeted therapy. The most promising new assay measures soluble, low-molecular weight VEGF-A isoforms that was shown to be of predictive value in the retrospective evaluation of breast, pancreatic and gastric cancer specimens (Jayson et al, 2011). Prospective evaluations in breast and lung cancer are under way, however, no data are available with ovarian cancer so far.

\section{CONCLUSION}

The treatment of patients with ovarian cancer continues to be challenging. Opportunities identified in the molecular microcosm of neoplastic pathways yields many promising targets. Evaluation of the action of a range of targeted agents in ovarian cancer is underway. The anti-angiogenic drugs are driving the field with the recent licensing of bevacizumab in first- and second-line treatment in Europe. The activity of bevacizumab in ROC evokes considerable potential for future therapeutic strategies although refinement of details such as optimal timing of treatment, combinations with other agents, duration of treatment and payment for this is urgently required to inform safest and best practice. The work has just begun!

\section{REFERENCES}

Aghajanian C, Blank SV, Goff BA, Judson PL, Teneriello MG, Husain A, Sovak MA, Yi J, Nycum LR (2012) OCEANS: a randomised, doubleblinded, placebo-controlled, phase III trial of chemotherapy with or without bevacizumab in patients with platinum sensitive recurrent epithelial ovarian, primary peritoneal or fallopian tube cancer. J Clin Oncol 30: 2039-2045.

Aghajanian C, Blank SV, Goff BA, Judson PL, Nycum LR, Sovak MA, Yi J, Hussain A (2012) An updated safety analysis of OCEANS, a randomised double-blinded, phase III trial of gemcitabine and carboplatin with bevacizumab or placebo followed by bevacizumab or placebo to disease progression in patients with platinum sensitive recurrent ovarian cancer. J Clin Onc 30(suppl): abstr 5054 .

Belotti D, Vergani V, Drudis T, Borsotti P, Pitelli MR, Viale G, Giavazzi R, Taraboletti G (1996) The microtubule-affecting drug paclitaxel has antiangiogenic activity. Clin Cancer Res 2(11): 1843-1849.

Biagi JJ, Oza AM, Chalchal HI, Grimshaw R, Ellard SL, Lee U, Hirte H, Sederias J, Ivy SP, Eisenhauer EA (2011) A phase II study of sunitinib in patients with recurrent epithelial ovarian and primary peritoneal carcinoma: an NCIC Clinical Trials Group Study. Ann Oncol 22(2): 335-340.

Bornstein P (1995) Diversity of function is inherent in matricellular proteins: an appraisal of thrombospondin 1. J Cell Biol 130(3): 503-506.

Burger RA, Sill MW, Monk BJ, Greer BE, Sorosky JI (2007) Phase II trial of bevacizumab in persistent or recurrent epithelial ovarian cancer or primary peritoneal cancer: a Gynecologic Oncology Group Study. J Clin Onc 25: 5165-5171.

Burger RA, Brady MF, Bookman MA, Fleming GF, Monk BJ, Huang H, Mannel RS, Homesley HD, Fowler J, Greer BE, Boente M, Birrer MJ, Liang SX (2011) The incorporation of bevacizumab in the primary treatment of ovarian cancer. N Engl J Med 365: 2473-2483.

Cannistra SA, Matulonis UA, Penson RT, Hambleton J, Dupont J, Mackey H, Douglas J, Burger RA, Armstrong D, Wenham R, McGuire W (2007) Phase II study of bevacizumab in patients with platinum-resistant ovarian cancer or peritoneal serous cancer. J Clin Oncol 25(33): 5180-5186. 
Cassidy J, Saltz LB, Giantonio BJ, Kabbinavar FF, Hurwitz HI, Rohr UP (2010) Effect of bevacizumab in older patients with metastatic colorectal cancer: pooled analysis of four randomized studies. J Cancer Res Clin Oncol 136: 737-743.

Chura JC, Van Iseghem K, Downs Jr LS, Carson LF, Judson PL (2007) Bevacizumab plus cyclophosphamide in heavily pretreated patients with recurrent ovarian cancer. Gynaecol Oncol 107(2): 326-330.

Cobleigh MA, Langmuir VK, Sledge GW, Miller KD, Haney L, Novotny WF, Reimann JD, Vassel A (2003) A phase I/II dose-escalation trial of bevacizumab in previously treated metastatic breast cancer. Semin Oncol 30: $117-124$.

Cohn AL, Bekaii-Saab T, Bendell JC, Hurwitz H, Kozloff N, Roach H, Tezcan S, Feng A, Sing A, Grothey A (2010) Clinical outcomes in bevacizumab treated patients with metastatic colorectal cancer: results from ARIES observational cohort study and confirmation of BRiTE data on BV beyond progression. J Clin Oncol 28(15s suppl): abstr 3596.

Colombo. N (2011) Efficacy of trabectidin in platinum-sensitive relapsed ovarian cancer: new data from the randomised OVA-301 study. Int J Gyn Oncol 21: S12-S16.

Cortes J, Calvo V, Ramirez-Merino N, O’Shaughnessy J, Brufsky A, Robert N, Vidal M, Munoz E, Perez J, Dawood S, Saura C, Di Cosimo S, Gonzalez-Martin A, Bellet M, Silva OE, Miles D, Llombart A, Baselga J (2012) Adverse events associated with bevacizumab adddition to breast cancer chemotherapy: a meta- analysis. Annals of Onc 23: 1130-1137.

de Gramont A, de Gramont A, Chibaudel B, Bachet J-B, Larsen AK, Tournigand C, Louvet C, Andre T. for GERCOR (French Oncology Research Group) (2011) Targeted therapy in adjuvant treatment for stage III colon cancer. Semin Oncol 38(4): 521-532.

Diaz JP, Tew WP, Zivanovic O, Konner J, Sabbatini PJ, dos Santos LA, Abu-Rustum NR, Chi DS, Aghajanian C, Barakat RR (2010) Incidence and management of bevacizumab-associated gastrointestinal perforations in patients with recurrent ovarian carcinoma. Gynecol Oncol 116: $335-339$.

Duska LR, Garrett L, Henretta M, Ferris JS, Lee L, Horowitz N (2010) When 'never-events' occur despite adherence to clinical guidelines: the case of venous thromboembolism in clear cell cancer of the ovary compared with other epithelial histologic subtypes. Gyn Oncol 116: 374-377.

Ebos JML, Lee CR, Cruz-Munoz W, Bjarnason GA, Christensen JG, Kerbel RS (2009) Accelerated metastasis after short-term treatment with a potent inhibitor of tumor angiogenesis. Cancer Cell 15(3): 232-239.

Friedlander M, Hancock KC, Rischin D, Messing MJ, Stringer CA, Matthys GM, Ma B, Hodge JP, Lager JJ (2010) A Phase II, open-label study evaluating pazopanib in patients with recurrent ovarian cancer. Gynecol Oncol 119: 32-37.

Gaitskell K, Martinek I, Bryant A, Kehoe S, Nicum S, Morrison J (2011) Angiogenesis inhibitors for the treatment of ovarian cancer. Cochrane Database Syst Rev 9: CDD007930.

Garcia AA, Hirte H, Fleming G, Yang D, Tsao-Wei DD, Roman L, Groshen S, Swenson S, Markland F, Gandara D, Scudder D, Morgan R, Chen H, Lenz HJ, Oza AM (2008) Phase II clinical trial of bevacizumab and lowdose metronomic oral cyclophosphamide in recurrent ovarian cancer: a trial of the California,Chicago, and Princess Margaret Hospital phase II consortia. J Clin Oncol 26: 76-82.

Giantonio BJ, Catalano PJ, Meropol NJ, O'Dwyer PJ, Mitchell EP, Alberts SR, Schwartz MA, Benson AB (2007) High-dose bevacizumab improves survival when combined with FOLFOX4 in previously treated advanced colorectal cancer: results from the Eastern Cooperative Oncology Group (ECOG) study E3200. J Clin Oncol 25: 1539-1544.

Grothey A, Sugrue MM, Purdie DM, Dong W, Sargent D, Hedrick E, Kozloff M (2008) Bevacizumab beyond first progression is assoiciated with prolonged overall survival in metastatic colorectal cancer: results from a loarge observational cohort study (BRiTE). J Clin Onc 26: 5326-5334.

Hall M, Rustin G (2010) A retrospective review of low dose oral cyclophosphamide alone and in combination with tamoxifen and prophylactic warfarin in heavily pretreated ovarian cancer. Int J Gyn Cancer 20((suppl)): abstr 467.

Han ES, Monk BJ (2007) What is the risk of bowel perforation associated with bevacizumab therapy in ovarian cancer? Gynecol Oncol 105: 3-6.

Hashimoto K, Man S, Xu P, Cruz-Munoz W, Tang T, Kumar R, Kerbel RS (2010) Potent preclinical impact of metronomic low-dose oral topotecan combined with the antiangiogenic drug pazopanib for the treatment of ovarian cancer. Mol Cancer Ther 9(4): 996-1006.

Hensley M (2011) Big costs for little gain in ovarian cancer. J Clin Onc 29: $1230-1232$.

Horsman MR, Siemann DW (2006) Pathophysiologic effects of vasculartargeting agents and the implications for combination with conventional therapies. Cancer Res 66(24): 11520-11539.

Hurt JD, Richardson DLR, Seamon LG, Fowler JF, Copeland LJ, Cohn DE, Eisenhauer E, Salani R, O’Malley DM (2009) Sustained progression-free survival with weekly paclitaxel and bevacizumab in recurrent ovarian cancer. Gynecol Oncol 115: 396-400.

Hurwitz HI, Salt LB, Van Cutsem E, Cassidy J, Wiedemann J, Sirzen F, Lyman GH, Rohr UP (2011) Venous thromboembolic events with chemotherapy plus bevacizumab: a pooled analysis of patients in randomised phase II and III studies. J Clin Onc 29(13): 1757-1764.

Jain RK (2005) Antiangiogenic therapy for cancer: current and emerging concepts. Oncology (Williston Park) 19(4 Suppl 3): 7-16.

Javier Cortes MC, Delaloge S, Cortes-Funes H, Pierga J-Y, Pritchard K, Bollag DT, Miles DW (2012) Safety of bevacizumab in metastatic breast cancer patients undergoing surgery. Eur J Cancer 48: 475-481.

Jayson GC, de Haas S, Delmar P, Miles DW, Shah MA, Van Cutsem E, Carmeliet P, Hegde P, Wild N, Scherer SJ (2011) Evaluation of plasma VEGFA as a pan-tumour biomarker for the treatment of patients with bevacizumab. ESMO/ECCO Sweden, 2011 Abstr 804.

Kabbinavar FF, Flynn PJ, Kozloff M, Ashby MA, Sing A, Barr CE, Grothey A (2012) Gastrointestinal perforation associated with bevacizumab use in metastatic colorectal cancer: Results from a large treatment observational cohort study. Eur J Cancer 48: 1126-1132.

Karlan BY, Oza AM, Richardson GE, Provencher DM, Hansen VL, Buck M, Chambers SK, Ghatage P, Pippitt Jr CH, Brown 3rd JV, Covens A, Nagarkar RV, Davy M, Leath 3rd CA, Nguyen H, Stepan DE, Weinreich DM, Tassoudji M, Sun YN, Vergote IB (2012) Randomized, double-blind, placebo-controlled phase II study of AMG 386 combined with weekly paclitaxel in patients with recurrent ovarian cancer. J Clin Oncol 30(4): $362-371$.

Katsumata N, Yasuda M, Takahashi F, Isonishi S, Iobo T, Aoki D, Tsuda H, Sugiyama T, Kodama S, Kimura E, Ochiai K, Noda K. for the JGOG (2012) Dose-dense paclitaxel once a week in combination with carboplatin every 3 weeks for advanced ovarian cancer: a phase 3, open-label, randomised controlled trial. J Clin Oncol 30(suppl): abstr 5003.

Khorana AA, Dalal M, Lin J, Connolly GC (2012) Incidence and predictors of venous thomboembolism (VTE) among ambulatory high-risk cancer patients undergoing chemotherapy in the United States. Cancer; e-pub ahead of print 14 August 2012; doi:10.1002/cncr.27772.

Kobold S, Hegewisch-Becker S, Oechsle K, Jordan K, Bokemeyer C, Atanackovic D (2009) Intraperitoneal VEGF inhibition using bevacizumab: a potential approach for the symptomatic treatment of malignant ascites? Oncologist 14(12): 1242-1251.

Kristensen G, Perren T, Qian W, Pfisterer J, Ledermann JA, Joly F, Carey MS, Beale PJ, Cervantes A, Oza AM. for GCIG (2012) Result of interim analysis of overall survival in the GCIG ICON7 phase III randomized trial of bevacizumab in women with newly diagnosed ovarian cancer. J Clin Onc 30(suppl): abstr 5006.

Le T, Hopkins L, Baines KA, Rambout L, Al Hayki M, Kee Fung MF (2006) Prospective evaluations of continuous weekly paclitaxel regimen in recurrent platinum-resistant epithelial ovarian cancer. Gynecol Oncol 102(1): 49-53.

Ledermann JA, Hackshaw A, Kaye S, Jayson G, Gabra H, McNeish I, Earl H, Perren T, Gore M, Persic M, Adams M, James L, Temple G, Merger M, Rustin G (2011) Randomized phase II placebo-controlled trial of maintenance therapy using the oral triple angiokinase inhibitor BIBF 1120 after chemotherapy for relapsed ovarian cancer. J Clin Oncol 29(28): 3798-3804.

Lortholary A, Largillier R, Weber B, Gladieff L, Alexandre J, Durando X, Slama B, Dauba J, Paraiso D, Pujade-Lauraine E. on behalf of GINECO group France (2011) Weekly paclitaxel as a single agent or in combination with carboplatin or weekly topotecan in patients with resistant ovarian cancer: the CARTAXHY randomized phase II trial from Groupe d'Investigateurs Nationaux pour l'Etude des Cancers Ovariens (GINECO). Ann Oncol 23(2): 346-352.

Matei D, Sill MW, Lankes HA, DeGeest K, Bristow RE, Mutch D, Yamada SD, Cohn D, Calvert V, Farley J, Petricoin EF, Birrer MJ (2011) Activity of sorafenib in recurrent ovarian cancer and primary peritoneal carcinomatosis: a Gynecologic Oncology Group trial. J Clin Oncol 29(1): 69-75. 
Matulonis UA, Berlin S, Ivy P, Tyburski K, Krasner C, Zarwan C, Berkenbilt A, Campos S, Horowitz N, Cannistra SA, Lee H, Lee J, Roche M, Hill M, Whalen C, Sullivan L, Tran C, Humphreys BD, Penson RT (2009) Cediranib, an oral inhibitor of vascular endothelial growth factor receptor kinases, is an active drug in recurrent epithelial ovarian, fallopian tube, and peritoneal cancer. J Clin Oncol 27: 5601-5606.

McKeage MJ (2011) Clinical trials of vascular disrupting agents in advanced non-small-cell lung cancer. Lung Cancer 12(3): 143-147(3): 143-147.

Merritt WM, Nick AM, Carroll AR, Lu C, Matsuo K, Dumble M, Jennings N, Zhang S, Lin YG, Spannuth WA, Kamat AA, Stine RL, Shahzad MMK, Coleman RL, Kumar R, Sood AK (2010) Bridging the gap between cytotoxic and biologic therapy with metronomic topotecan and pazopanib in ovarian cancer. Mol Camcer Ther 9(4): 985-995.

Miles D, Bridgewater J, Ellis P, Harrison M, Nathan P, Nicolson M, Raouf S, Wheatley D, Plummer C (2010) Using Bevacizumab to treat metastatic cancer: UK consensus guidelines. Br J Hosp Med 71(12): 670-677.

Miles D, Harbeck N, Escudier B, Hurwitz H, Saltz L, Van Cutsem E, Cassidy J, Mueller B, Sirzen F (2011) Disease course patterns after discontinuation of bevacizumab: pooled analysis of randomized phase III trials. J Clin Oncol 29: 83-88.

Miller KD, Sweeney CJ, Sledge GW (2001) Redefining the target: chemotherapeutics as antiangiogenics. J Clin Oncol 19(4): 1195-1206.

Nakayama G, Uehara K, Ishigure K, Yokoyama H, Ishiyama A, Eguchi T, Tsuboi K, Ohashi N, Fuji T, Sugimoto H, Kolke M, Fujiwara M, Abdo Y, Kodera Y (2012) The efficacy and safety of bevacizumab beyond first progression in patients treated with first-line mFOLFOX6 followed by second-line FOLFIRI in advanced colorectal cancr: a multicentre, single-arm,phase II trial (CCOG-0801). Cancer Chemother Pharmacol 70(4): $575-581$.

O’Malley DM, Richardson DL, Rheaume PS, Salani R, Eisenhauer EL, McCann GA, Fowler JM, Copeland LJ, Cohn DE, Backes FJ (2011) Addition of bevacizumab to weekly paclitaxel significantly improves progression-free survival in heavily pretreated recurrent epithelial ovarian cancer. Gynecol Oncol 121(2): 269-272.

Okines A, Langley RE, Thompson LC, Stenning SP, Stevenson L, Falk S, Seymour M, Coxon FY, Middleton GW, Smith D, Evans L, Slater S, Waters JS, Ford D, Hall M, Iveson T, Petty RD, Plummer C, Allum W, Cunningham D. The National Cancer Research Institute (NCRI) Upper GI Cancers Clinical Studies Group (2011) Safety results from a randomised trial of preoperative epirubicin, cisplatin plus capecitabine with or without bevacizumab in patients with gastric or type II/III oesophagogastric junction adenocarcinoma. Ann Oncol; e-pub ahead of print 28 October 2012; doi:10.1093/annonc/mds533.

Pasquier E, Honore S, Pourroy B, Jordan MA, Lehmann M, Briand C, Braguer D (2005) Antiangiogenic concentrations of paclitaxel induce an increase in microtubule dynamics in endothelial cells but not in cancer cells. Cancer Res 65(6): 2433-2440.

Pegram M, Liao J (2012) Trastuzumab treatment in multiple lines: current data and future directions. Clin Breast Cancer 12(1): 10-18.
Perren TJ, Swart AM, Pfisterer J, Ledermann JA, Pujade-Lauraine E, Kristensen G, Carey MS, Beale P, Cervantes A, Kurzeder C, du Bois A, Sehouli J, Kimmig R, Stähle A, Collinson F, Essapen S, Gourley C, Lortholary A, Selle F, Mirza MR, Leminen AR, Plante M, Stark D, Qian W, Parmar MKB, Oza AM for the ICON7 Investigators* (2011) A phase 3 trial of bevacizumab in ovarian cancer. $N$ Engl J Med 365: 2484-2496.

Pujane-Lauraine E, Hilpert F, Weber B, Reuss A, Poveda A, Kristensen G, Sorio R, Vergote I, Witteveen P, Bamias A, Pereira D, Wimberger P, Oaknin A, Mirza MR, Follana P, Bollag D. Ray-Coquard I on behalf of the ENGOT-GCIG investigators (2012) AURELIA: a randomised phase III trial evaluating bevacizumab combined with chemotherapy for platinumresistant recurrent ovarian cancer. J Clin Oncol 30(suppl): abstr LBA5002.

Richardson DL, Backes FJ, Hurt JD, Seamon LG, Copeland LJ, Fowler JM, Cohn DE, O'Malley DM (2010) Which factors predict bowel complications in patients with recurrent epithelial ovarian cancer being treated with bevacizumab? Gynecol Oncol 118: 47-51.

Rustin GJ, Bradley C, Galbraith S, Stratford M, Loadman P, Waller S, Bellenger K, Gumbrell L, Folkes L, Halbert G. Phase I/II Trials Committee of Cancer Research UK (2003) 5,6-dimethylxanthenone-4-acetic acid (DMXAA), a novel antivascular agent: phase I clinical and pharmacokinetic study. Br J Cancer 88(8): 1160-1167.

Sandler AB, Gray R, Perry M, Brahmer J, Schiller JH, Dowlati A, Lilenbaum R, Johnson DH (2006) Paclitaxel -carboplatin alone or with bevacizumab for non-small-cell-lung cancer. N Engl J Med 355: 2542-2550.

Sfakianos GP, Numnum TM, Halverson CB, Panjeti D, Kendrick IV JE, Straughn Jr JM (2009) The risk of gastrointestinal perforation and/or fistula in patients with recurrent ovarian cancer receiving bevacizumab compared to standard chemotherapy: a retrospective cohort study. Gynecol Oncol 114: 424-426.

Tillmans TD, Reed ME, Privett MC, Johns AL, Walker MS, Houts AC (2012) Phase I trial of metronomic oral topotecan in combination with pazopanib utilizing a daily dosing schedule to treat recurrent or persistent gynaecologic tumors. J Clin Onc 30(suppl): abstr 5014.

Vassilakopoulou M, Mountzios G, Papamechael C, Protogerou AD, Aznaouridis K, Katsichti P, Venetsanou K, Dimopoulos MA, Ikonomidis I, Papadimitriou CA (2010) Paclitaxel chemotherapy and vascular toxicity as assessed by flow-mediated and nitrate-mediated vasodilatation. Vascul Pharmacol 53(3-4): 115-121.

Zweifel M, Jayson GC, Reed NS, Osborne R, Hassan B, Ledermann J, Shreeves G, Poupard L, Lu SP, Balkissoon J, Chaplin DJ, Rustin GJ (2011) Phase II trial of combretastatin A4 phosphate, carboplatin, and paclitaxel in patients with platinum-resistant ovarian cancer. Ann Oncol 22(9): 2036-2041.

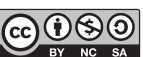
This work is licensed under the Creative Commons Attribution-NonCommercial-Share Alike 3.0 Unported License. To view a copy of this license, visit http://creativecommons. org/licenses/by-nc-sa/3.0/ 